\title{
Perros de la calle. El precio de la irresponsabilidad
}

\author{
José Ignacio Soto Peredo \\ Universidad de Concepción, Carrera de Medicina Veterinaria, Casilla 160-C, Concepción, Chile. \\ Fundacion Vox Animalis
}

Resumen

El presente trabajo expone una visión crítica sobre la relación de los habitantes de Chile para con sus mascotas, específicamente los perros. Se trata de una problemática vigente en la sociedad, a la que no se le ha dado la prioridad que le corresponde, ya que influye directamente en la calidad de vida de las personas, pero también da testimonio de los valores morales, cívicos y éticos de la población del país basados en la forma de asumir responsabilidades, que en este caso se trata de una responsabilidad de por vida por tratarse de seres vivos completamente dependientes del hombre. En este informe se hace referencia a la situación de los perros abandonados tanto en ciudades como en otras áreas geográficas y al impacto que éstos tienen sobre la vida de las personas y sobre la naturaleza, haciendo hincapié en el hecho de que se trata de animales domésticos, lo que conduce al origen de esta problemática, el hombre en sociedad. Por otra parte, se presenta una serie de medidas concretas que servirían como herramientas para un posible plan de acción para enfrentar dicha problemática, las que dependen sobretodo de la voluntad política de las autoridades, quienes a pesar de estar en conocimiento de esta situación permanecen pasivas, salvo excepciones. Esto puede tener como causa la poca experiencia enfrentando problemas relacionados con animales, empeorado por el hecho de que el hombre cada día tiene menos contacto con la naturaleza, por lo que no hay una experiencia sobre la que basar una futura solución. Todo esto nos lleva a la importancia del aspecto educativo para suplir la falta de conocimiento de la población y de las autoridades, ya que se hace necesario un cambio cultural para llegar a un cambio de paradigma en nuestra relación con los animales, donde el trabajo de educación y sensibilización parecen ser las herramientas más efectivas si nos basamos en las experiencias de otras sociedades más avanzadas en este aspecto.

\section{Abstract}

This paper presents a critical view of the pet-owner relationship in Chile, specifically as regards dogs. This is a real problem in the society, the solution of which has not been given the priority it deserves in spite of the fact that it affects the quality of life of people directly, but also testifies to the moral, civic and ethical values of the population of the country based on the way it assumes responsibility, which, in this case, ought to be lifelong, since the objects in question are living beings completely dependent on man. This report refers to the situation of abandoned dogs both in cities and in other geographical areas and their impact on the lives of people and on nature, emphasizing the fact that the subjects referred to are pets. This leads us to the root - cause of the problem: man in society. Moreover, a number of concrete measures are presented in order to serve as tools for a possible plan of action to address this problem where the political will of the authorities plays a critical role, since despite their being made aware of this situation, they have still remained passive, apart from rare exceptions. This may be caused by the lack of experience of such people in facing problems related to animals, accentuated by the ever decreasing daily contact of humans with nature, which results in no experience to base a future solution on. All this leads us to the importance of the educational aspect to compensate for the lack of knowledge in the population and its authorities, since a cultural change is necessary in order to achieve a paradigm shift in the way we interact with animals. Raising awareness and performing educational work seem to be the most successful tools at the moment in solving the problem of abandoned dogs, especially if we draw on the experience of societies that have shown greater progress in this respect.

¿A quién no le ha pasado que va por alguna calle y de pronto no poder avanzar a causa de algún perro intimidante?, prácticamente a todos nos ha sucedido. Cuando con mi familia adoptamos nuestro primer perro, lo primero que hicimos fue llevarlo al veterinario. Como tenía más de 3 meses cuando llegó y era un perro grande en cuanto a peso y tamaño, lo llevé al veterinario a pie. A poco avanzar noté que había demasiados perros en las calles y no iba por una población marginal ni nada parecido, como podría esperarse. No importaba por donde fuera, 
plazas, centro, poblaciones, etc., todas las calles estaban llenas de perros con o sin dueño, y como éstos consideran que la calle es su territorio, se vuelven agresivos si ven acercarse a un perro que no es del sector (Manteca, 2002), lo que claramente no es agradable porque se forma una verdadera orquesta de amenazantes ladridos. Durante el resto del trayecto al veterinario me hice un mapa mental armando una ruta lo más tranquila y segura posible para poder pasear en paz con mi mascota, mi mapa incluía conocer a todos los perros en las calles desde mi casa hasta la clínica veterinaria.

Desde que comencé a pasear a mi perro ya no pude hacer vista gorda al hecho de que en las calles de nuestro país, la población de perros es alarmante, tanto así que la cantidad de recursos que se debe invertir para revertir las consecuencias de estos animales es considerable. Un ejemplo de esto son las sumas de dinero que se gastan en mordeduras de perros, unos $\$ 2.000$ millones al año (Provoste, 2014). Según un estudio realizado en la ciudad de Santiago solo en 2003 la tasa promedio anual de mordeduras fue de 1.262 por 100.000 habitantes (Ibarra et al, 2003). Todo esto deriva en gastos por concepto de atenciones médicas, hospitalizaciones y vacunaciones contra la principal zoonosis para el humano: la rabia. Según datos de la OMS, en la mayoría de los casos fatales de rabia humana han sido los perros la principal fuente de infección (OMS, Nota descriptiva $\mathrm{N}^{\circ} 99,2014$ ). Otra consecuencia para las personas derivada del ataque de perros son las secuelas psicológicas que en muchas ocasiones deben ser tratadas debido a que se transforman en verdaderos traumas para las víctimas. Los perros $\sin$ sujeción también hacen que algunas zonas sean intransitables para los peatones y representan un peligro para los automovilistas que intentan esquivarlos, pudiéndose desatar verdaderas tragedias.

Por otra parte, en las ciudades, como consecuencia del abandono o de la críanza de perros en las calles, como se hace comúnmente, se originan grandes problemas de higiene producto del aumento de fecas en las calles y del esparcimiento de basura de origen humano (Bonacic \& Abarca, 2014), esto último como comportamiento legítimo de los perros en su intento de cubrir sus necesidades alimenticias básicas, lo que, sin embargo, trae como consecuencia focos de insalubridad acompañados de malos olores (Soto, 2013). Esto además se puede transformar en un riesgo epidemiológico por el aumento de roedores e insectos, sin olvidar el riesgo que significan los desechos en descomposición en la vía pública.

En los casos en que los perros son abandonados en las periferias de las ciudades o en sectores rurales, se contribuye a la formación de verdaderas jaurías, las que dependiendo del sector donde se encuentren, pueden llegar a producir pérdidas económicas significativas para la agricultura, donde los mayores afectados son los pequeños campesinos que viven de sus animales. A esto se debe agregar que los animales también son abandonados en zonas donde habitan especies nativas en estado salvaje, las que corren serio peligro cuando los perros se transforman en verdaderos cazadores de su alimento, los llamados perros asilvestrados (Bonacic \& Alvarado, 2011).

Al considerar las consecuencias negativas que trae la población sin control de perros en las calles, entiéndase dentro de esta clasificación para efectos prácticos tanto perros callejeros, vagabundos como asilvestrados, se hace evidente que se trata de un problema transversal en la sociedad, ya que abarca todos los ámbitos y estratos socioeconómicos. Es la consecuencia lógica y visible de la irresponsabilidad de la ciudadanía para con otras personas, porque en sociedad nuestros actos afectan inevitablemente a nuestros semejantes y para con sus mascotas, en este caso, los perros, por ser estos animales domésticos. Los perros tienen la particularidad de depender casi en un $100 \%$ de los humanos para poder sobrevivir. Existen algunas razas de perros salvajes (ejemplo: dingo), originarios de otras latitudes, pero éstas no se encuentran en Chile ni en Sudamérica. En el resto de tipos de perros solo existen excepciones que pueden sobrevivir por sí mismas sin atención del hombre (Boitani \& Ciucci, 1995). Es importante mencionar que para que los perros puedan sobrevivir al abandono humano, el animal ya debe haberse desarrollado físicamente. En otras palabras, solo los animales que ya han crecido lograrán sobrevivir, un cachorro pequeño no lo logrará.

En la vida cotidiana es fácil encontrar personas que manifiestan la intención de deshacerse de sus mascotas, unos lo hacen porque ya son muy grandes y dejaron de ser ese juguetito adorable, otros porque crecieron tanto ellos como sus fecas o porque orinan mucho, ladran sin parar y por más que les griten no se callan, otros se cambian o amplían sus casas y los perros ya no caben, el veterinario es demasiado caro, etc. A modo de ejemplo de casos de abandono, sucedió que mientras hacía voluntariado en la Sociedad Protectora de Animales de Curicó, amarraron en la puerta a un perro adulto, blanco con un papel que decía lo siguiente: "Mi nombre es Ángel, me enfermé y mis dueños no tienen para gastos del veterinario", después de un examen veterinario, su diagnóstico fue que el perro estaba delgado, casi desnutrido y su enfermedad era la falta de alimento. Posteriormente fue dado 
en adopción y se recuperó comiendo de forma normal, no había otras enfermedades que justificaran la nota y menos el abandono.

De esto se puede deducir que el único responsable de la actual situación de los perros es el hombre. Es importante mencionar que éste no es un problema exclusivo de nuestro país, basta echar un vistazo a lo que sucede en otros países como España, donde con la Ley 50/1999 ya se regularizó este tema, lo que dice mucho de la diferencia entre España y Chile porque cada país hace las leyes según el grado de civilización y complejidad de sus habitantes (Lahera, 2002). En este país europeo, antes de llevar a cabo cualquier medida, se hizo primero un diagnóstico serio y un reconocimiento de la problemática para elaborar un plan de acción (Tamayo, 1997).

Los diferentes análisis serios que se han hecho de la situación de los perros en Chile, ya sea en un debate entre estudiantes de Medicina Veterinaria o a nivel gubernamental, dan como resultado que el sacrificio de estos animales no es una solución eficiente. El sacrificio por envenenamiento ha sido históricamente la única forma de control de la población canina en Chile desde 1918 con un fin meramente sanitario (Soto, 2013), la que se ha llevado a cabo de forma sistemática y regular en todo el país. Cabe destacar que además de ineficiente, esta medida es también ilegal, ya que por ley está prohibida. Estos actos ilegales son ahora más visibles debido a la intervención de la prensa, sin embargo, siguen sin documentarse puesto que no son de conveniencia para sus autores, que por lo general son las mismas autoridades y, por ende, nunca hay responsables. Los responsables tienen que ocultar su identidad para proteger su imagen y aunque cada cierto tiempo estas muertes ilegales o algún caso de maltrato impactante producen una enorme efervescencia mediática promovida por organizaciones animalistas que instalan en la palestra un pequeño debate social, al poco tiempo se disuelve y la situación vuelve a ser la misma de antes, lo que perjudica cualquier proyecto de ley a favor de las mascotas o de los animales, y nuestros legisladores dejan en el olvido el tema hasta que se produce el siguiente caso impactante. Este comportamiento social no solo impacta negativamente a los animales sino también a las personas.

Nuevamente quiero señalar que el sacrificio no es la alternativa adecuada para controlar la población de perros de la calle, éste es un problema que debe abordarse de manera integral desde distintos flancos y desde sus orígenes. El sacrificio de estos animales ya se practica en Estados Unidos, donde no hay perros en las calles, pero no porque se haya controlado la población canina. Cada año se sacrifican en EEUU cientos de miles de mascotas abandonadas en las perreras estatales (American Human Association, 2015), porque en ese país tampoco se ha producido un cambio conductual en las personas, solo aplican una solución superficial al problema y las víctimas, los animales, son castigadas con la muerte, mientras que los culpables se libran de toda culpa sin merecerlo. En Europa, sin embargo, la cantidad de animales sí es menor, ya que no cualquiera puede reproducir ni vender mascotas.

Una solución integral para este problema debe incluir los siguientes puntos básicos:

Primero: Leyes que velen por el bienestar de nuestras mascotas, con sanciones de multas y penas de cárcel para quienes sean maltratadores, eliminando así la ineficiente ley vigente (Ley 20.380, Sobre Protección de Animales) sobre maltrato animal, porque mientras los animales sean considerados "cosas" (Soto, 2013), no son sujetos de derecho. Estudios prueban que alguien que ha maltratado a algún miembro de su familia probablemente no cambiará y en el caso de los animales es prácticamente imposible porque tanto hombres como mujeres reconocen que practican la violencia, aunque a la vez la rechazan (Duarte et al, 2010). Esto es aún más alarmante si consideramos que los estudios confirman que culturalmente en nuestra sociedad la violencia forma parte de la educación por parte de los padres, es decir que educamos a través del maltrato infantil (UNICEF, 2015). En dicha ley también debe incluirse un registro de razas potencialmente peligrosas debido a que el carácter del animal dependerá de su crianza, por lo que el propósito de dicho registro es asegurar que el propietario sea apto para tener un animal específico.

Segundo: Se deben hacer campañas de esterilizaciones masivas de machos y hembras, derribando mitos sobre cuándo es el momento adecuado para estilizar y hacerlo lo antes posible. El gobierno chileno actual es el único que ha destinado recursos para dicho propósito mediante licitaciones concursables en distintas ciudades como Angol, Curicó, entre otras. Si bien esto es un avance significativo, está lejos de ser suficiente (Bonacic \& Abarca, 2014), puesto que con esta medida se ataca un síntoma del problema no el origen.

Tercero: Es necesaria la puesta en marcha de campañas publicitarias incentivando las adopciones en lugar de la compra de mascotas para promover la tenencia responsable y el verdadero amor por los animales.

Cuarto: Se debe legislar para limitar con criterios claros, la reproducción y venta de mascotas, ya hay suficientes animales en Chile y la venta de mascotas va también contra los principios de bienestar animal, ya que los animales, en este caso los perros, no son productos, no deben reproducirse en masa y su número se debe reducir. Solo los criaderos que cumplan estrictas exigencias deben poder vender mascotas. 
Quinto: El punto más importante es la educación de los niños de forma sistemática y sostenida en el tiempo. Un par de folletos que terminarán en la basura no son de ninguna forma la medida más eficiente de provocar un cambio. Educar es la forma de promover el cambio conductual que conducirá a un cambio cultural, esto se debe realizar sobre todo en los niveles básicos de la escolaridad, ya que a esa edad existe una mayor receptividad por parte de las personas a nuevos conocimientos, puesto que es la etapa en donde se produce el desarrollo cerebral (Schunk, 2012).

Mi experiencia me ha mostrado la alegría espontánea y el impacto positivo que tiene en los niños ver entrar a la sala de clases a nuevos "tíos y tías" acompañados de una hembra canina, rescatada y adoptada de la calle, el contarles sobre su abandono por parte de algún adulto (porque no son los niños quienes abandonan), el enseñarles con el ejemplo lo que es ser una persona empática y responsable, el llevar y compartir con alegría en el aula la experiencia de hacer lo correcto para que se transforme en nuevo conocimiento y el ver el entusiasmo al final de nuestras intervenciones cuando los niños y niñas ya no solamente quieren jugar o acariciar a una perrita, sino que también esperan con ansias su turno para pasearla de forma correcta con una cadena de sujeción. En mi opinión, la gente no se imagina el efecto positivo que produce en los niños compartir con una mascota, si lo imaginaran pasearían a sus mascotas con sus hijos a diario, les enseñarían que el amor también es una cuestión práctica, no es solo regalos o caricias, sabrían que amor también significa responsabilidad y respeto, serían conscientes de lo que implica esa responsabilidad, podrían decidir si adoptar o no una mascota y comprenderían que una responsabilidad no necesariamente tiene que ser aburrida. En una sociedad donde cada vez se diferencia menos entre el precio y el valor que tienen las cosas y los actos, donde la moral y la ética son solo mitos, los animales pueden ser la esperanza al final del día, porque son capaces de sacar del embobamiento de la tecnología y del materialismo para disfrutar de la vida de forma plena. Tan solo el vaivén de la cola de un perro al ver llegar a su amo puede traer de vuelta la humanidad al humano.

\section{Referencias}

American Human Association. Animals, Fact Sheets, Animal Shelter Euthanasia http://www.americanhumane.org/animals/stop-animal-abuse/fact-sheets/animal-shelter-euthanasia.html.

(Visitado 27 de julio, 2015).

Bonacic, C. \& C. Abarca. 2014. Hacia una política y legislación para el control de poblaciones de cánidos y calidad de vida de las personas: un enfoque multidisciplinario. Centro de Políticas Públicas UC, Chile. 65:1-14.

Boitani, L. \& P. Ciucci. 1995. Comparative social ecology of feral dogs and wolves. Ethology, Ecology \& Evolution, Italia. 7:49-72.

Bonacic, C. \& R. Alvarado. 2011. Investigación y educación sobre el impacto de los perros en ambientes naturales. Fondo de Protección Ambiental, Ministerio del Medio Ambiente, Chile.

Calle, J. 2006. Evaluación de aspectos etológicos veterinarios y vínculo humano animal. Revista CES Medicina Veterinaria y Zootecnia, Colombia. 1:33-41.

Duarte, E., J. Gómez \& C. Carrillo. 2010. Masculinidad y hombre maltratador: ¿Pueden las creencias de hombres y mujeres propiciar violencia de género? Revista de Psicología de la Universidad de Chile, Chile. 19(2):7-30.

Ferrer, V., E. Bosch, M. Ramis \& C. Navarro. 2006. Las creencias y actitudes sobre la violencia contra las mujeres en la pareja: Determinantes sociodemográficos, familiares y formativos. Anales de Psicología, España. 22(2): 251-259.

Hundek, L. 2010. Violencia doméstica: hombres versus mujeres maltratantes en la ciudad de Barranquilla. Revista Pensamiento Americano, Colombia. 4:69-79.

Ibarra, L., F. Espínola \& M. Echeverría. 2006. Una prospección a la población de perros existentes en las calles de Santiago, Chile. Avances en Ciencias Veterinarias, Chile. 21:33-39.

Ibarra, L., M. Morales \& L. Cáceres. 2003. Mordeduras a personas por ataque de perros en la ciudad de Santiago, Chile. Avances en Ciencias Veterinarias, Chile. 18:41-46.

Lahera, E. 2002. Introducción a las Políticas Públicas. Primera edición. Fondo de cultura económica Chile S.A., Santiago, Chile 2002.

Manteca X, 2002.Etología clínica veterinaria del perro y del gato. Segunda edición. Facultad de Veterinaria, Universitat Autónoma de Barcelona, Barcelona, España.

OMS (Organización Mundial de la Salud), 2014. Temas de salud, Rabia, Nota descriptiva N99. http://www.who.int/mediacentre/factsheets/fs099/es/. (Citado el 25 de julio, 2015). 
Palacio, J., M. León \& S. García. 2004. Aspectos epidemiológicos de las mordeduras caninas. Gac Sanit, España. 19(1):50-58.

Provoste, C. 2011.Análisis de la responsabilidad por el hecho de los animales en Chile. Tesis de Licenciado, Facultad de Derecho, Departamento de Derecho Privado, Universidad de Chile, Santiago, Chile.

Schunk, D. 2012. Teorías del aprendizaje: Una perspectiva educativa. Sexta edición. University of North Carolina, Greensboro.

Soto, A. 2013. Análisis de un problema público no abordado: El caso de los perros vagabundos y callejeros en Chile. Tesis de Magister, Facultad de Ciencias Físicas y Matemáticas, Departamento de Ingeniería Industrial, Universidad de Chile, Santiago, Chile.

Tamayo, M. 1997: El Análisis de las Políticas Públicas. La nueva administración Pública.

http://es.scribd.com/doc/27756759/El-Analisis-de-las-Politicas-Publicas. (Citado el 03 de agosto, 2015).

UNICEF, 2015. $4^{\circ}$ Estudio de maltrato infantil en Chile: Análisis comparativo 1994-2000-2006-2012. Dirección de Estudios Sociológicos, Pontificia Universidad Católica de Chile, Chile. 